\title{
Consumption pattern of nuts-the noble antioxidants sources
}

\author{
PRACHI AVINASH AND KUSUM MITTAL
}

Received: 20.06.2017; Revised: 24.10.2017; Accepted: 09.11.2017

See end of the paper for authors' affiliations

\section{PRACHI AVINASH}

Department of Home Science, Govt. Meera Girls College (M.L.S.U.),

UDAIPUR (RAJASTHAN) INDIA

Email : prachiabhatnagar@

gmail.com
ABSTRACT : Epidemiological studies have provided evidence of an inverse association between plants based diets and degenerative diseases. The content and concentration of antioxidantsin nuts suggest the beneficial role they play in health promotion and disease prevention. These benefits though evident to scientists and the other handful of people, the knowledge among the customer population might not be sufficient in order to modify their dietary habits and patterns. Thus, there was a felt need of assessing the consumption practices of consumers regarding the utilization of nuts. The present study was therefore conducted in the Udaipur city of Rajasthan (India). The sample comprised of 100 respondents who were homemakers, actively involved in household cooking, who could provide crisp and authentic information. A questionnaire was prepared and the respondents were contacted personally. In conclusion, results revealed that though consumption of nuts was noteworthy among the population, the use was largely attributed to taste and flavor and the therapeutic or medicinal value (antioxidants) of nuts was not recognized by majority of respondents, which is of concern. Hence, it was understood that new strategiesare required to make aware the consumers about the therapeutic benefits of nuts and thus popularize the use. Future public health initiatives should be mindful of these consumption patterns.

KEY WORDS: Antioxidants, Nuts, Utilization, Medicinal value, Awareness

- HOW TO CITE THIS PAPER : Avinash, Prachi and Mittal, Kusum (2017). Consumption pattern of nuts-the noble antioxidants sources. Asian J. Home Sci., 12 (2) : 545-551, DOI: 10.15740/HAS/AJHS/ 12.2/545-551. 